\title{
EL CUIDADO DE LAS MUJERES MAYORES Hacia un sistema nacional de cuidados en México
}

\author{
THE CARE OF OLDER WOMEN \\ Towards a national system of care in Mexico
}

Ivonne Thaili Millán Barajas*

\begin{abstract}
RESUMEN: El trabajo doméstico y de cuidados que es realizado en su gran mayoría por las mujeres es invisibilizado y no es reconocido en una sociedad que privilegia el trabajo remunerado en el espacio público realizado, en gran medida, por los hombres. Este desprecio por el cuidado del hogar y la familia ocasiona que las mujeres vayan acumulando grandes desventajas a lo largo de su vida por lo que, al llegar a la vejez, experimentan con mayor recrudecimiento las desigualdades.
\end{abstract}

ABSTRACT: Unpaid domestic and care work, typically done by Women, is often invisible and unrecognized by a society that privileges paid work in public spaces. This work is carried out to no small extent by men. This disregard for domestic and care work causes women to accumulate significant disadvantages throughout their lives, leading them to experience incredibly stark inequalities when they reach old age.

PALABRAS CLAVE: Mujeres mayores, COVID-19, trabajo doméstico y de cuidados.

KEYWORDS: Older women, Covid-19, unpaid domestic and care work.

Fecha de recepción: 15/03/2021

Fecha de aceptación: 15/03/2021

doi: https://doi.org/10.20318/universitas.2021.6198

\footnotetext{
* Licenciada en Derecho por la Universidad Latinoamericana; Máster en Derechos Fundamentales por la Universidad Carlos III de Madrid; Máster en Estudios de Mujeres, Género y Ciudadanía con especialidad en políticas públicas por la Universidad de Barcelona, y Especialista en Migración y Derechos Humanos por la Universidad Nacional Autónoma de México. E-mail: ivonnetmb@gmail.com
} 
"Cuando se ha comprendido lo que es la condición de los viejos no es posible conformarse con reclamar una "política de la vejez" más generosa, un aumento de las pensiones, alojamientos sanos, ocios organizados. Todo el sistema es lo que está en juego y la reivindicación no puede sino ser radical: cambiar la vida"1.

Simone de Beauvoir

\section{1.- INTRODUCCIÓN}

El presente artículo tiene como objetivo plantear las desigualdades sociales y económicas que experimentan las mujeres mayores en México por el hecho de ser mujeres y ser mayores, así como el incremento de la violencia y las desigualdades con la llegada de la pandemia por Covid19. Asimismo, busca dar un acercamiento al Sistema Nacional de Cuidados que pretende instaurarse en México, muy posiblemente, en este año 2021.

Para poder hacer una comparativa que demuestre fácilmente las desigualdades entre mujeres y hombres se ha optado por recopilar algunos datos para demostrar cómo las mujeres mayores con el paso de los años han ido acumulando diversas desigualdades, por lo que al llegar a la vejez viven y experimentan esta etapa de una manera distinta a como lo hacen los hombres.

Las grandes desigualdades entre mujeres y hombres se deben a la división sexual del trabajo y a los roles de género que han relegado a las mujeres al ámbito doméstico y de cuidados, en donde realizan las labores más desgastantes como cocinar, lavar, planchar, cuidar, entre muchas otras y que son actividades que no son reconocidas ni valoradas en la sociedad capitalista y patriarcal ${ }^{2}$ en la que vivimos. Por otro lado, se observa que los hombres al dedicar su vida al ámbito público y gracias a que se beneficiaron del sistema que solo reconoce el trabajo formal y remunerado, tienen mayores ingresos y mejor estabilidad social y económica, por lo que cuando llegan a la edad adulta gozan de mejores condiciones que las mujeres mayores.

Por lo anterior, en el primer apartado se hablará de manera general sobre las personas mayores en México para conocer cuál es su situación laboral, económica y social actual en el país. En el segundo apartado se abordarán los derechos de las personas mayores en México,

\footnotetext{
${ }^{1}$ Simone de Beauvoir, La Vejez, (Debolsillo, 2016), p. 671.

2 En el artículo 'Trata de mujeres con fines de explotación sexual en México' proporciono una explicación relevante sobre los términos patriarcado y capitalismo (Ivonne Thaili Millán Barajas, 'Trata de mujeres con fines de explotación sexual en México', (2018) Revista Jurídica Jalisciense, año xxviii, núm. 59. Julio-diciembre.
} 
en donde se recogerá la Ley de los Derechos de las Personas Adultas Mayores y se hará un breve análisis sobre el derecho a la igualdad y no discriminación para luego proporcionar algunos datos que arrojan las diferentes discriminaciones que han experimentado las personas mayores en razón de su edad. Asimismo, en este apartado se recogerán algunos de los efectos que ha tenido la pandemia de Covid-19 en este grupo etario, incluyendo un breve análisis sobre la especial vulneración que han sufrido las mujeres mayores a raíz de la declaratoria de emergencia en marzo de 2020. Finalmente, en el tercer apartado, se recogerá la propuesta sobre el Sistema Nacional de Cuidados en México. Aquí, se ampliará la información sobre la desigual repartición de las tareas del hogar y de los cuidados y cómo esto ha afectado la vida de las mujeres, por lo que cuando llegan a la vejez experimentan grandes dificultades para gozar de una vida más digna.

\section{2.- LAS PERSONAS MAYORES EN MÉXICO}

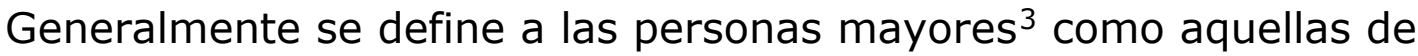
60 años o más, aunque dependiendo de las leyes internas de cada país, la edad para considerarse mayor puede variar, pero no puede ser superior a los 65 años ${ }^{4}$. En América Latina y el Caribe la población está experimentando un rápido crecimiento de las personas mayores. De acuerdo con la Comisión Económica para América Latina y el Caribe (CEPAL), "en la subregión hay 23.622 .000 personas de 60 años y más que representan el $28 \%$ de la población" 5 . En México, el $11 \%$ es población mayor. De acuerdo con las Proyecciones de la Población 20102050 del INEGI, para 2050, se estima que habrá un poco más de 32 millones de personas mayores en el país.

La Comisión Nacional de los Derechos Humanos (CNDH) señala que "[e]l hecho de llegar a la vejez no representa per se una desventaja o conflicto para las personas, pues se trata simplemente de una etapa más del ciclo de vida; sin embargo, el envejecimiento se puede ver

\footnotetext{
3 Aunque existen diversas denominaciones para referirse a las personas mayores como puede ser personas de edad avanzada, personas de más edad, personas de la tercera edad, ancianas, ancianos y personas de la cuarta edad para las personas mayores de 80 años, se ha optado por "personas mayores", al ser el término utilizado en las resoluciones $47 / 5$ y $8 / 98$ de la Asamblea General y al ser el término que se utiliza en la Convención Interamericana sobre la Protección de los Derechos Humanos de las Personas Mayores.

${ }^{4}$ Organización de las Naciones Unidas, Convención Interamericana sobre la Protección de los Derechos Humanos de las Personas Mayores, depositadada por la Secretaría General OEA y adoptada en Washington, D.C., Estados Unidos. Entró en vigor el 11 de enero de 2017.

5 CEPAL, COVID-19 y sus impactos en los derechos y la protección social de las personas mayores en la subregión, (2020), p.22.
} 
implicado con ciertos problemas sociales" ${ }^{\prime 6}$. Por ejemplo, cuando las personas mayores tienen alguna enfermedad crónica, grave o degenerativa, una discapacidad, cuando son aisladas o cuando se enfrentan a condiciones de pobreza. De hecho, un gran porcentaje de las personas mayores viven en situación de pobreza. En 2018, en América Latina y el Caribe el 23,1\% de las personas de 65 años y más se encontraban en situación de pobreza. En México, la cifra era del $34,2 \%{ }^{7}$. Es importante mencionar que un porcentaje las personas mayores no cuenta con ingresos propios.

La relación entre personas mayores y pobreza es estrecha. Esta relación está asociada al trabajo remunerado y no remunerado, al trabajo formal y al trabajo informal, a la cobertura de pensiones, jubilaciones, y al acceso a la seguridad social, principalmente. En la región, un gran número de personas mayores se desarrollan en trabajos precarios, no tienen acceso a la seguridad social, no juntan las cotizaciones que necesitan para gozar de una pensión o jubilación, y cuando llegan a una edad adulta se ven en la necesidad de seguir insertas en el mercado laboral, experimentando grandes desigualdades. De acuerdo con la CEPAL, en América Latina, el promedio de personas mayores que continúan en el mercado laboral es del $39,7 \%$ y tan solo en México el $41 \%$, es decir, México sobrepasa el promedio de América Latina ${ }^{8}$. El UNFPA señala que "en muchos casos es necesario que las personas mayores permanezcan en el mercado laboral, ya que las pensiones o jubilaciones resultan más bajas con respecto a los salarios devengados durante su vida laboral (y especialmente las mujeres) ${ }^{\prime \prime}{ }^{9}$. De ese gran porcentaje, según la CEPAL, en 2019, el $72,5 \%$ de las personas mayores se encontraba en el trabajo informal, lo que a su vez genera otras problemáticas pues a pesar de mantenerse de manera activa sus ingresos son bajos ${ }^{10}$. En México, de acuerdo con datos de la Encuesta Nacional sobre Discriminación (ENADIS) de $2017^{11}, 37,0 \%$ de las personas mayores dependen económicamente de sus hijas o hijos, $28.5 \%$ considera que la pensión que recibe es insuficiente para cubrir sus necesidades básicas y $22,5 \%$ refiere una falta de oportunidades para encontrar trabajo.

\footnotetext{
${ }^{6}$ Comisión Nacional de los Derechos Humanos, Informe Especial sobre la Situación de los Derechos Humanos de las Personas Mayores en México, (2019), p. 17.

7 CEPAL, Op. Cit., p. 28.

8 CEPAL, Op. Cit., p. 30.

'UNFPA, Una mirada sobre el envejecimiento. ¿Dónde están varios países latinoamericanos a 15 años del Plan de Acción Internacional de Madrid?, (2017), p. 26.

10 CEPAL, Op. Cit., p. 31.

${ }^{11}$ ENADIS 2017. Principales resultados. Disponible en:

https://www.inegi.org.mx/contenidos/programas/enadis/2017/doc/enadis2017 resulta dos.pdf (última consulta 12 de diciembre de 2020).
} 


\section{1.- Los Derechos de las personas mayores en México}

El 22 de agosto de 1979 se publicó en el Diario Oficial de la Federación (DOF) la creación del Instituto Nacional de la Senectud (INSEN) para atender las necesidades de las personas mayores. Años más tarde, cambió la denominación del INSEN, pero también se planteó otra política de atención hacia este grupo etario, por lo que se le denominó Instituto Nacional de Adultos en Plenitud (INAPLEN) ${ }^{12}$. Posteriormente, en 2002 se creó el Instituto Nacional de las Personas Adultas Mayores (INAPAM) como institución rectora de las políticas públicas en favor de las personas mayores, cuyo objetivo general es "coordinar, promover, apoyar, fomentar, vigilar y evaluar las acciones públicas, estrategias y programas que se deriven de ella, de conformidad con los principios, objetivos y disposiciones contenidas en la presente Ley"13.

La Ley de los Derechos de las Personas Adultas Mayores fue publicada en el DOF el 25 de junio de 2002 y está dividida en seis títulos: Disposiciones generales; De los principios y los derechos; De los deberes del Estado, la sociedad y la familia; De la política pública nacional de las personas adultas mayores; del Instituto Nacional de las Personas Adultas Mayores, y De las responsabilidades y sanciones. Aunque en teoría todas las personas mayores tienen reconocidos sus derechos, en la realidad, la restricción de los derechos y la desigual repartición de los recursos tiene un impacto significativo en la vida de todas la personas. A lo largo de la historia se ha discriminado a ciertos colectivos o grupos de personas, provocando con ello una desigualdad social. Así, en nuestras sociedades se generan discriminaciones por la clase social, el género, la raza y la etnia, la discapacidad, la orientación sexual y la edad ${ }^{14}$.

\subsection{1.- El derecho a la igualdad y no discriminación}

\footnotetext{
12 Senado de la República, Gaceta de la Comisión Permanente, Del Dip. Evelio Plata Inzunza, del Grupo Parlamentario del Partido Revolucionario Institucional, con proyecto de decreto que reforma el artículo 5o. de la Ley de los Derechos de las Personas Adultas Mayores. Disponible en:

<https://www.senado.gob.mx/64/gaceta comision permanente/documento/81611> (última consulta 12 de diciembre de 2020).

13 Ley de los Derechos de las Personas Adultas Mayores, publicada en el DOF el 25 de junio de 2002, Art. 25.

14 John Baker y otros, Equality: From Theory to Action (New York, MacMillan, 2004).
} 
El derecho a la igualdad y no discriminación está recogido en el artículo $1^{\circ}$ de la Constitución Política de los Estados Unidos Mexicanos, mismo que reza:

"Queda prohibida toda discriminación motivada por origen étnico o nacional, el género, la edad, las discapacidades, la condición social, las condiciones de salud, la religión, las opiniones, las preferencias sexuales, el estado civil o cualquier otra que atente contra la dignidad humana y tenga por objeto anular o menoscabar los derechos y libertades de las personas."

Si bien la Constitución no recoge la edad como criterio, lo cierto es que señala algunos criterios de manera enunciativa mas no limitativa, y además contempla "cualquier otra que atente contra la dignidad humana y tenga por objeto anular o menoscabar los derechos y libertades de las personas", por lo que en ésta cabría la edad. Al respecto, la Corte Interamericana de Derechos Humanos en el caso Poblete Vilches y otros Vs. Chile, ha señalado que, en relación a la Convención Americana de Derechos Humanos, ésta tampoco contempla de manera expresa la edad como criterio de no discriminación, sin embargo,

\footnotetext{
"Ios criterios específicos en virtud de los cuales está prohibido discriminar, según el artículo 1.1 de la Convención Americana, no son un listado taxativo o limitativo sino meramente enunciativo. Por el contrario, la redacción de dicho artículo deja abiertos los criterios con la inclusión del término "otra condición social" para incorporar así a otras categorías que no hubiesen sido explícitamente indicadas". Así, la Corte ha señalado que la edad, es también una categoría protegida por esta norma. En este sentido, la prohibición por discriminación relacionada con la edad cuando se trata de las personas mayores, se encuentra tutelada por la Convención Americana"15.
}

A nivel internacional, la Declaración Universal de los Derechos Humanos; el Pacto Internacional de Derechos Económicos, Sociales y Culturales, y el Pacto Internacional de Derechos Civiles y Políticos contemplan el derecho a la no discriminación por raza, color, sexo, idioma, religión, opinión política o de cualquier otra índole, origen nacional o social, posición económica, nacimiento o cualquier otra condición (énfasis añadido). La Carta de Derechos Fundamentales de la Unión Europea, por ejemplo, contempla la no discriminación por motivos de sexo, raza, color, orígenes étnicos o sociales, características genéticas, lengua, religión o convicciones, opiniones políticas o de cualquier otro tipo, pertenencia a una minoría nacional, patrimonio, nacimiento, discapacidad, edad u orientación sexual.

15 Corte Interamericana de Derechos Humanos, Cuadernillo de Jurisprudencia de la Corte Interamericana de Derechos Humanos No. 14: Igualdad y No Discriminación, (2019), p. 71. 
Los derechos a la igualdad y no discriminación son, en esencia, principios básicos de los derechos humanos, y como tales son; universales, inalienables, irrenunciables, intransferibles, imprescriptibles e indivisibles. De tal suerte que toda persona, per se, goza de ellos, y ni particulares ni autoridades pueden actuar en su detrimento. Los derechos a la igualdad y no discriminación están íntimamente relacionados y anulando uno de estos se anula el otro en consecuencia.

La Segunda Sala de la Suprema Corte de Justicia de la Nación $(\mathrm{SCJN})$ ha señalado que "[e]ste principio de igualdad y no discriminación opera en el sistema jurídico de manera transversal; es decir, al permear a todo el ordenamiento, impone diversos deberes a las autoridades del Estado"16, y agrega que "[I]a igualdad, como principio constitucional, subyace en toda la estructura del sistema jurídico y, por tanto, constituye un límite a los poderes del Estado conforme al cual debe cuidarse el no generar paridad entre todos los individuos (igualdad formal o jurídica), ni tampoco una igualdad material o real, sino que exige razonabilidad en la diferencia de trato"17. Así mismo, el Pleno de la SCJN, al respecto, ha dicho en la Acción de Inconstitucionalidad 8/2014 que:

"De conformidad con el parámetro de regularidad constitucional principio a la igualdad y la no discriminación éste permea todo el ordenamiento jurídico. Así, cualquier tratamiento que resulte discriminatorio respecto del ejercicio de cualquiera de los derechos garantizados en la Constitución es per se incompatible con la misma. Así pues, es incompatible toda situación que, por considerar superior a un determinado grupo, conduzca a tratarlo con algún privilegio, o que, inversamente, por considerarlo inferior, se le trate con hostilidad o de cualquier forma lo discrimine del goce de derechos que sí se reconocen a quienes no se consideran incursos en tal situación"18 (énfasis añadido).

Por su parte, la Corte Interamericana de Derechos Humanos (Corte IDH), "ha establecido que los Estados deben abstenerse de realizar acciones que de cualquier manera vayan dirigidas, directa o indirectamente, a crear situaciones de discriminación de jure o de facto" 19 .

La CNDH define la discriminación como "dar un trato distinto a las personas que en esencia son iguales y gozan de los mismos derechos;

16 Segunda Sala de la Suprema Corte de Justicia de la Nación, Amparo en Revisión 710/2016, Ministro: Javier Laynez Potisek, p. 16.

17 Ídem.

18 Pleno de la Suprema Corte de Justicia de la Nación, Acción de inconstitucionalidad 8/2014. Ministra Margarita Beatriz Luna Ramos, párrs. 55 y 61.

19 Corte Interamericana de Derechos Humanos, Caso Espinoza Gonzáles Vs. Perú. Sentencia de 20 de Noviembre de 2014 (Excepciones Preliminares, Fondo, Reparaciones y Costas), párr. 220. 
ese trato distinto genera una desventaja o restringe un derecho a quien lo recibe"20. La Ley de los Derechos de las Personas Adultas Mayores en el artículo 8 señala que "[n]inguna persona adulta mayor podrá ser socialmente marginada o discriminada en ningún espacio público o privado por razón de su edad, género, estado físico, creencia religiosa o condición social." Por su parte, la Ley Federal para prevenir y eliminar la discriminación es más amplia en su concepto y refiere que:

\begin{abstract}
"se entenderá por discriminación, toda distinción, exclusión, restricción o preferencia que, por acción u omisión, con intención o sin ella, no sea objetiva, racional ni proporcional y tenga por objeto o resultado obstaculizar, restringir, impedir, menoscabar o anular el reconocimiento, goce o ejercicio de los derechos humanos y libertades, cuando se base en uno o más de los siguientes motivos: el origen étnico o nacional, el color de piel, la cultura, el sexo, el género, la edad, las discapacidades, la condición social, económica, de salud o jurídica, la religión, la apariencia física, las características genéticas, la situación migratoria, el embarazo, la lengua, las opiniones, las preferencias sexuales, la identidad o filiación política, el estado civil, la situación familiar, las responsabilidades familiares, el idioma, los antecedentes penales o cualquier otro motivo" 21 .
\end{abstract}

De tal suerte, "[I]a igualdad y la no discriminación son dos de los principios y derechos más fundamentales del derecho internacional de los derechos humanos. Dado que están intrínsecamente conectados con la dignidad humana, [y] son la piedra angular del resto de los derechos humanos"22.

A pesar de lo anterior, las personas mayores sufren desigualdades y discriminaciones en razón de su edad, misma que se agrava cuando converge con otros criterios de discriminación como por ejemplo una mujer mayor indígena con discapacidad. En México, la Encuesta Nacional sobre Discriminación (ENADIS) ${ }^{23}$, señaló que el $57 \%$ de las personas mayores consideran que sus derechos se respetan poco o nada. Además, el 16,1\% refirió que ha sufrido discriminación en al menos un ámbito social, entre los que se mencionan la calle o el transporte público, el trabajo o la escuela, y en la familia. El $24,8 \%$ de las personas mayores declararon al menos un incidente relacionado con

20 Comisión Nacional de los Derechos Humanos, El derecho a la no discriminación, (2018), p. 6.

${ }^{21}$ Ley Federal para prevenir y eliminar la discriminación, publicada en el DOF el 13 de junio de 2002, Art. 1 fracción III.

22 Comité sobre los Derechos de las Personas con Discapacidad, Observación general núm. 6 (2018) sobre la igualdad y la no discriminación, CRPD/C/GC/6, (26 de abril de 2018), párr.4

${ }^{23}$ ENADIS 2017, Op. Cit. 
la negación de sus derechos en los últimos cinco años ${ }^{24}$. Un $61,1 \%$ de las personas mayores refirió haber experimentado al menos una situación de discriminación en razón de su edad, y un $82.0 \%$ señaló que la mayoría de la gente se desespera con una persona mayor. La Organización Mundial de la Salud (OMS) ha señalado que "las personas de edad también pueden ser discriminadas por motivos de edad en las decisiones relativas a la atención médica, el triaje y los tratamientos vitales" 25 .

Uno de los objetivos de la Política Nacional sobre personas adultas mayores en México es

"[f]omentar en la familia, el Estado y la sociedad, una cultura de aprecio a la vejez para lograr un trato digno, favorecer su revalorización y su plena integración social, así como procurar una mayor sensibilidad, conciencia social, respeto, solidaridad y convivencia entre las generaciones con el fin de evitar toda forma de discriminación y olvido por motivo de su edad, género, estado físico o condición social"26.

Sin embargo, las diversas manifestaciones de discriminación y violencia hacia las personas mayores son el reflejo del pensamiento social, pero también de las políticas públicas deficientes que no han logrado erradicar estas situaciones que aquejan a un gran porcentaje de las personas mayores en México. Además, el hecho de que el Estado Mexicano no haya firmado y ratificado la Convención Interamericana sobre la Protección de los Derechos Humanos de las Personas Mayores es también un indicador de su falta de compromiso hacia las personas mayores.

\section{2.- Las personas mayores, las más afectadas por la pandemia por Covid-19}

En diciembre de 2019, estalló el brote del virus SARS-Cov-2, también conocido como Covid-19 en Wuhan, China. De acuerdo con la OMS, la Covid-19 es una enfermedad infecciosa causada por el coronavirus que ocasiona infecciones respiratorias ${ }^{27}$.

\footnotetext{
${ }^{24}$ De acuerdo con el documento, los principales derechos negados declarados fueron relacionacionados con la atención médica o medicamentos, recibir apoyos de programas sociales y la atención en oficinas de gobierno.

25 Organización de las Naciones Unidas, Informe de políticas: Los efectos de la COVID19 en las personas de edad, (2020), p. 3.

26 Ley General de las Personas Adultas Mayores, Op. Cit., Art. 10, VII.

27 Organización Mundial de la Salud, Preguntas y respuestas sobre la enfermedad por coronavirus (COVID-19), Disponible en:

<https://www.who.int/es/emergencies/diseases/novel-coronavirus-2019/advice-forpublic/q-acoronaviruses?gclid=CjwKCAiAxeX BRASEiwAc1QdkWEIXjGmCMNScBJ] Ibp6oL1ZtYou
} 
La CEPAL ha señalado que "independiente de la región del mundo de la que se trate, las personas mayores han sido el grupo más afectado por la pandemia en términos de la gravedad de la enfermedad y el número de muertes"28.

En México ${ }^{29}$, las defunciones se han centrado en las personas de 60 años y más. "Entre las personas fallecidas por COVID-19, la condición médica subyacente más prevalente fue la hipertensión, seguida de la diabetes y problemas cardiovasculares, aunque se presentaron algunos cambios por grupos de edad"30. Sin embargo,

"no solo las condiciones de salud y el envejecimiento ponen en peligro a las personas mayores. La soledad como emoción y el aislamiento como condición estructural en la que viven muchas de ellas juegan un papel importante frente a su capacidad de responder a la enfermedad. La falta de respuesta de los sistemas de salud pueden ser un factor coadyuvante para empeorar la situación" ${ }^{31}$.

La emergencia sanitaria por Covid-19 acrecentó las desigualdades para las personas mayores ${ }^{32}$ y dejó en evidencia que la vulnerabilidad no es únicamente por su edad, sino que también está relacionada con las condiciones económicas en las que se encuentren, su estado de salud y la respuesta de cada país frente a la pandemia. Como parte de la respuesta ante la Covid-19, México decretó emergencia sanitaria en marzo de 2020 y estableció que la población en riesgo, entre ellas las personas mayores, debían de permanecer en casa para evitar el riesgo

MF71wUSS9VB HVz6kAY2fg7WBoCBn8QAvD BwE> (última visita 15 de diciembre de 2020).

${ }^{28}$ CEPAL, Op. Cit., p. 50.

29 "Los datos de México indican además que existen impactos diferenciales del COVID19 entre personas indígenas y no indígenas en todas las edades (...) No hay que olvidar que antes de la pandemia las comunidades indígenas ya experimentaban un acceso deficiente a la atención médica, tasas significativamente más altas de enfermedades transmisibles y no transmisibles, falta de acceso a servicios esenciales, saneamiento y otras medidas preventivas clave como agua potable, jabón, desinfectante, entre otros." (CEPAL, Op. Cit., p. 60).

30 CEPAL, Op. Cit., p. 57.

31 CEPAL, COVID-19 Recomendaciones generales para la atención a personas mayores desde una perspectiva de derechos humanos, (2020 a), p. 9.

32 De acuerdo con la ONU, "Las personas de edad que pasan la cuarentena o el confinamiento con sus familiares o cuidadores pueden también estar expuestas a un riesgo mayor de sufrir violencia, malos tratos y descuido. Las que viven en condiciones precarias -como en campamentos de refugiados, asentamientos informales y prisiones- corren un riesgo particular debido a las condiciones de hacinamiento, el acceso limitado a los servicios de salud y a las instalaciones de agua y saneamiento, así como las posibles dificultades para acceder al apoyo y la asistencia humanitarios." (Organización de las Naciones Unidas (2020) Op. Cit., p. 3. 
de contagio y dictó una serie de medidas de protección ${ }^{33}$. Asimismo, como parte de la respuesta, la Secretaría de Bienestar continuó entregando la pensión para el bienestar a las personas mayores ${ }^{34}, y$

adelantó el pago del bimestre de mayo-junio, por lo que recibieron $\$ 5,240$ pesos mexicanos en el bimestre de marzo-abril. Si bien la pensión para las personas mayores es una fuente de ingresos, ésta solo se brinda a 8 millones de personas mayores ${ }^{35}$, dejando a muchas de ellas fuera, además de que solamente se otorga a personas mayores de 68 años en adelante y en el caso de personas mayores que viven en zonas rurales, a partir de los 65 años $^{36}$. De acuerdo con la Secretaría de Salud, todas las personas de 60 años y más forman parte del grupo de riesgo $^{37} \mathrm{y}$, sin embargo, las personas mayores de 60 a 67 años en el caso de la población que vive en zonas urbanas y de 60 a 64 en el caso de quienes viven en zonas rurales no son beneficiarias de la pensión para el bienestar que otorga la Secretaría de Bienestar.

La vulnerabilidad económica también se ha hecho más evidente con la llegada de la Covid-19. En el primer trimestre de 2020, 83 mil personas mayores dejaron sus lugares de trabajo de manera temporal o permanente 38 , lo que implica que no tendrán ese ingreso para cubrir sus necesidades y las de sus familias.

33 Gobierno de México, Quédate en Casa. Disponible en:

$<$ https://coronavirus.gob.mx/quedate-en-casa/> (última visita el 26 de diciembre de 2020).

34 El presupuesto aprobado en 2020 para este programa fue de 129 mil millones de pesos.

35 Gobierno de México, Programa de Pensión para el Bienestar de las Personas Adultas Mayores. Disponible en: <https://presidente.gob.mx/programa-de-pension-para-elbienestar-de-las-personas-adultas-mayores/> (última visita el 26 de diciembre de 2020).

${ }^{36}$ Gobierno de México, Pensión Universal para Personas Adultas Mayores. Disponible en: <https://www.gob.mx/pensionpersonasadultasmayores> (última visita el 26 de diciembre de 2020).

37 Gobierno de México, Adultos Mayores. Disponible en:

$<$ https://coronavirus.gob.mx/adultos-mayores/> (última visita el 26 de diciembre de 2020).

38 Francisco Alberto Perez Pacheco y Alejandra Macias Sánchez, Adultos mayores y COVID-19: Vulnerabilidad económica ante la crisis sanitaria, (Centro de Investigación Económica y Presupuestaria, A. C., 2020) Disponible en: <https://ciep.mx/adultosmayores-y-covid-19-vulnerabilidad-economica-ante-la-crisis-sanitaria/> (última visita 27 de diciembre de 2020). 
Asimismo, la Organización de Naciones Unidas (ONU) ha señalado que la pandemia por Covid-19 ha afectado de diferentes maneras a las personas mayores en su bienestar económico, su salud mental, e incluso su integridad personal; tal y como se representa en el siguiente gráfico:

\section{GRÁFICO 1: EFECTOS DE LA COVID-19 EN LAS PERSONAS DE EDAD}

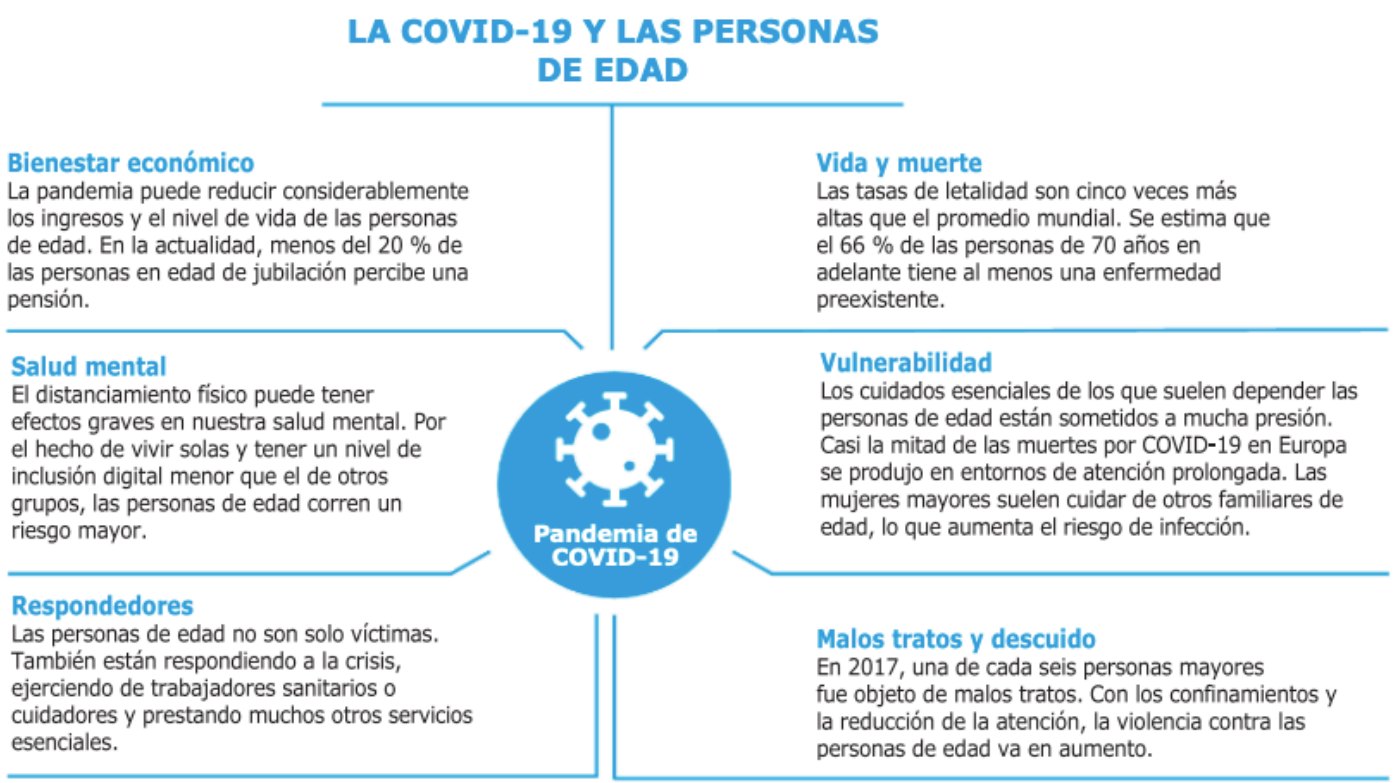

Fuente: Organización de las Naciones Unidas (2020).

Aunque en principio las medidas determinadas por México parecen acertadas y siguen la lógica de evitar contacto con otras personas al no salir de casa, recibir una pensión y tener un ingreso en momentos de incertidumbre, la realidad ha demostrado que muchas personas mayores son el sostén de las familias, trabajan en el sector informal y necesitan salir a ganar el sustento o bien, muchas de ellas se desempeñan en servicios esenciales o son cuidadoras de otras personas. Muchas personas mayores viven con sus familias nucleares o ampliadas en donde por lo menos algún miembro debe de salir y por lo tanto hay un riesgo latente de contagio. Ante estas situaciones que han hecho evidente que las personas mayores no son un grupo homogéneo, la OMS ha señalado que hay "que garantizar que las personas mayores sean protegidas de COVID-19 sin estar aisladas, estigmatizadas, dejadas en una situación de mayor vulnerabilidad o sin poder acceder a las disposiciones básicas y a la atención social"39. Asimismo, la ONU

${ }^{39}$ CEPAL (2020 a), Op. Cit., p. 9. 
decretó cuatro prioridades de acción ${ }^{40}$ para hacer frente a los efectos de la pandemia por Covid-19 en las personas mayores: 1) Velar por que las difíciles decisiones de atención sanitaria que afectan a las personas de edad se guíen por el compromiso con la dignidad y el derecho a la salud; 2) Reforzar la inclusión social y la solidaridad durante el distanciamiento físico; 3) Integrar plenamente las cuestiones relacionadas con las personas de edad en la respuesta socioeconómica y humanitaria a la COVID-19 y, 4) Ampliar la participación de las personas de edad, compartir buenas prácticas y aprovechar conocimientos y datos.

Las acciones que plantea la ONU son un claro ejemplo de cómo incorporar la óptica de derechos humanos en todos los asuntos que conciernen a las personas mayores, por lo que es importante que todas las políticas públicas y las respuestas de los Estados tengan como eje garantizar los derechos de las personas mayores y que no se centren única y exclusivamente en aspectos de salud, sino en otros aspectos como los sociales, los económicos e incluso los recreativos ${ }^{41}$.

\subsection{1.- Las mujeres mayores en la pandemia}

Las mujeres, al igual que en otros fenómenos, desastres naturales, crisis económicas, crisis políticas y crisis humanitarias, se ven afectadas de una manera diferenciada al resto de la población. Tal es el caso de la pandemia por Covid-19, en donde han experimentado mayores índices de violencia ${ }^{42}$, por lo que

"ha sido necesario afrontar la intensificación de la violencia por razón de género contra las mujeres y las niñas agravada por las medidas de confinamiento,

\footnotetext{
40 ONU (2020), Op. Cit.

${ }^{41}$ De acuerdo con la CEDAW, "en muchos países, la discriminación por motivo de edad se sigue tolerando y aceptando en los planos individual, institucional y normativo, y pocos países tienen leyes que prohíban la discriminación basada en la edad." (Comité para la Eliminación de la Discriminación contra la Mujer, Recomendación general No 27 sobre las mujeres de edad y la protección de sus derechos humanos, CEDAW/C/GC/27, 16 de diciembre de 2010, párr. 15).

42 "Los datos previos a la crisis provocada por el COVID-19 muestran la persistencia de la violencia hacia las mujeres y las niñas como una "pandemia en la sombra" a nivel mundial y regional donde en promedio 1 de cada 3 mujeres ha sido sometida $o$ vive violencia física, psicológica y/o sexual, por un perpetrador que era o es su pareja, lo que siempre conlleva el riesgo de la violencia letal: el feminicidio o femicidio." ( CEPAL (2020 b), Enfrentar la violencia contra las mujeres y niñas durante y después de la pandemia de Covid-19 requiere FINANCIAMIENTO, RESPUESTA, PREVENCIÓN Y RECOPILACIÓN DE DATOS, p. 3) Ver también, Equis Justicia para las Mujeres (2020), Las dos pandemias. Violencia contra las mujeres en México en el contexto de Covid-19. Disponible en: <http://equis.org.mx/wp-content/uploads/2020/08/informedospandemiasmexico.pdf> (última visita el 28 de diciembre de 2020).
} 
distanciamiento físico y las restricciones de movilidad que aumentaron el aislamiento de las mujeres de sus redes de apoyo y han generado barreras adicionales en el acceso a servicios esenciales" ${ }^{43}$.

De acuerdo con la Experta Independiente sobre el disfrute de todos los derechos humanos por las personas de edad, Claudia Mahler, "[I]as mujeres mayores en particular han sufrido violencia durante la crisis"44, además de que "[I]a prevalencia de múltiples formas concomitantes y agravadas de discriminación contra las personas de edad se suma a la alta incidencia de la pobreza y el aislamiento que sufren, especialmente en el caso de las mujeres de edad"45.

Por otra parte, las mujeres mayores son "[q]uienes normalmente reciben atención en casa y en la comunidad -como las mujeres de más de 80 años de edad que tienen más del doble de probabilidades que los hombres de vivir solas- $[\mathrm{y}]$ corren el riesgo de verse desproporcionadamente afectadas por las medidas de distanciamiento físico"46. Además,
"las personas de edad también suelen ejercer de cuidadores para hacer frente a la pandemia, por lo que corren un riesgo mayor de contraer el virus. Así es en el caso de las personas de edad - mayoritariamente mujeres- que han de ejercer de cuidadoras de otras personas de edad en el hogar, especialmente en contextos caracterizados por la fragilidad de sus sistemas de salud y atención prolongada"47.

La pandemia ha traído consigo una crisis económica que ha afectado ha un gran porcentaje de la población mexicana, pero que se ha agudizado para las personas mayores quienes, como se señaló en apartados precedentes, tienen mayores dificultades para tener una estabilidad económica. No obstante, según lo señalado por la Experta Independiente sobre el disfrute de todos los derechos humanos por las personas de edad, Claudia Mahler,

"[I]as repercusiones económicas de la pandemia afectarán considerablemente a las personas de edad y probablemente agravarán las múltiples formas de discriminación y la elevada incidencia de la pobreza y el aislamiento que sufre

\footnotetext{
${ }^{43}$ CEPAL (2020 b), Op. Cit., p. 1. Cit., párr. 65.

46 Organización de las Naciones Unidas (2020), Op. Cit., p. 3.

47 Ídem.
}

44 Organización de las Naciones Unidas, Informe de la Experta Independiente sobre el disfrute de todos los derechos humanos por las personas de edad, Claudia Mahler, Impacto de la enfermedad por coronavirus (COVID-19) en el disfrute de todos los derechos humanos por las personas de edad, A/75/205, 21 de julio de 2020, párr. 48.

45 Organización de las Naciones Unidas, Informe de la Experta Independiente sobre el disfrute de todos los derechos humanos por las personas de edad, Claudia Mahler, Op. 
este grupo de población, especialmente en el caso de las mujeres de edad y las personas mayores que tienen alguna discapacidad" 48 .

\section{3.- UNA DEUDA CON LAS MUJERES MEXICANAS}

La sostenibilidad de la vida humana, es una "actividad compleja realizada en el hogar que permite a las personas crecer, desarrollarse y mantenerse como tales"49. La sostenibilidad de la vida humana es, en realidad, la base de toda economía. Sin embargo, en una sociedad patriarcal como lo es la mexicana, las labores domésticas y de cuidados siempre se han considerado no productivas.

En un ejercicio interesante, Marçal explica que Adam Smith, el padre de la ciencia económica, quien acuñó el término de la "mano invisible" pasó por alto la pregunta sobre "cómo llegamos a tener nuestra comida en la mesa"50. La economía se basa en el estudio de los mercados y en cómo el homo economicus "pretende describir esa conciencia puramente económica que todos y cada uno de nosotros albergamos" 51 . Marçal nos explica que el hombre económico "es racional y se guía por el sentido común; no hace nada a lo que no esté obligado, y actúa para tener placer o evitar el dolor. Abre las manos para coger todo aquello que puede y hace todo lo posible para superar, ganar $y$, en última instancia, destruir a los que se interponen en su camino"52. Este hombre económico "posee todas las características que nuestra cultura atribuye tradicionalmente a la masculinidad: es racional, distante, objetivo, competitivo, solitario, independiente, egoísta, se guía por el sentido común y está dispuesto a conquistar el mundo"53. De acuerdo con Marçal, el homo economicus carece de todo aquello que está asociado a las mujeres o a la feminidad, es decir, "sentimiento, cuerpo, dependencia, comunidad, abnegación, ternura, naturaleza, imprevisibilidad, pasividad, conexión" 54 .

La invisibilidad de las labores que realizan las mujeres en el seno de los hogares ha contribuido a perpetuar grandes desigualdades entre mujeres y hombres. Los estereotipos de género han impuesto que las mujeres deben de realizar ciertas actividades, todas ellas enfocadas al

\footnotetext{
48 Organización de las Naciones Unidas, Informe de la Experta Independiente sobre el disfrute de todos los derechos humanos por las personas de edad, Claudia Mahler, Op. Cit., párr. 68.

49 María Inés Amoroso Miranda; Anna Bosch Pareras; Cristina Carrasco Bengoa y otras, Malabaristas de la vida. Mujeres, tiempos y trabajos, Grupo "Dones i Treballs de Ca la Dona, Barcelona (ICARIA, 2003).

50 Katrine Marçal, ¿Quién le hacía la cena a Adam Smith? (Debate, 2016), p. 27.

${ }^{51}$ Katrine Marçal, Op. Cit., p. 34.

52 Ídem.

53 Katrine Marçal, Op. Cit., p. 48.

${ }^{54}$ Katrine Marçal, Op. Cit., p. 49.
} 
cuidado de otros seres humanos con todo lo que eso implica. Mientras que, por otro lado, los hombres han gozado de una mayor libertad para circular en el ámbito público, en donde han logrado tener un estatus y reconocimiento que los posiciona en un ámbito de mayor poder y jerarquía frente a las mujeres.

Partiendo del sistema machista y patriarcal que existe en México, desde diciembre de 2019 hasta octubre de 2020, se presentaron diferentes ${ }^{55}$ iniciativas en materia de "reconocimiento del Derecho al Cuidado Digno y al Tiempo Propio"56. La base de las iniciativas es reconocer el trabajo doméstico y de cuidados que, por siglos, han realizado las mujeres. Así como hacerle frente a su distribución inequitativa bajo un sistema patriarcal que no ha reconocido como pilares fundamentales de la sociedad las labores de limpiar, coser, cocinar, lavar, planchar, gestionar y organizar el hogar, ni el cuidado de las y los miembros de la familia que realizan, en su gran mayoría, mujeres y niñas.

La iniciativa aprobada por la Cámara de Diputados el 18 de noviembre de 2020 con 329 votos a favor, 0 en contra y 0 abstenciones ${ }^{57}$, plantea que es

"indispensable atender esta problemática desde el principio de corresponsabilidad del Estado, del mercado, de las comunidades y de los hogares, desde una visión que coloque en el centro la despatriarcalización de los cuidados, la sostenibilidad de la vida, la vida digna de las personas, la erradicación de la desigualdad de derechos e inequidad del uso del tiempo entre hombres y mujeres, y desde un enfoque interseccional de derechos humanos"58.

Agrega que es indispensable tener en cuenta "[I]os cambios en las estructuras familiares y de la organización tradicional de los cuidados, el envejecimiento de la población y las políticas reduccionistas hacia políticas públicas de seguridad social"59, y propone reformar el artículo

55 La primera fue el 12 de diciembre de 2019, posteriormente, el 7 de abril, el 17 de junio, el 14 de septiembre y el 15 de octubre, todas de 2020.

56 Cámara de Diputados, Comisión de Puntos Constitucionales. Proyecto de Dictamen de las Comisión de Puntos Constitucionales por el que se reforman los artículos 40 Y 73 de la Constitución Política de los Estados Unidos Mexicanos, en materia de Sistema Nacional De Cuidados.

57 Cámara de Diputados [Mx_Diputados]. (18 de noviembre de 2020). 329 votos a favor, 0 en contra y 0 abstenciones. Aprueban, en lo general, el dictamen que reforma y adiciona los artículos 4 y 73 de la Constitución Política, en materia de sistema nacional de cuidados. [Tuit]. Recuperado de:

<https://twitter.com/Mx Diputados/status/1329244153658699776?ref src=twsrc\%5E tfw\%7Ctwcamp\%5Etweetembed\%7Ctwterm\%5E1329244153658699776\%7Ctwgr\%5E \%7Ctwcon\%5Es1 \&ref url=https\%3A\%2F\%2Fwww.milenio.com\%2Fpolitica\%2Fsiste ma-nacional-cuidados-avalado-camara-diputados $>$

58 Cámara de Diputados, Comisión de Puntos Constitucionales. Op. Cit.

59 Ídem. 
$4^{\circ}$ de la Constitución Política de los Estados Unidos Mexicanos, teniendo en cuenta las desigualdades, la crisis de cuidados, el contexto de inseguridad y violencia, el uso inequitativo del tiempo, la relevancia de los cuidados, el cuidado como derecho humano, y la existencia de una corresponsabilidad entre el Estado, el mercado, la familia y la comunidad. La iniciativa está dirigida a:

"todas las personas [que] son sujetas de cuidados, ponderando su contexto sociocultural, económico, geográfico, etario, entre otros, desde una mirada integral, donde las poblaciones prioritarias guardan una mayor jerarquía por condiciones específicas, tales como las poblaciones de personas mayores, menores, enfermas o con alguna discapacidad, sin dejar de visibilizar sus contextos e intersecciones" 60 .

Teniendo en cuenta que todas las personas necesitan de cuidados a lo largo de sus vidas, la iniciativa plantea la perspectiva de interculturalidad, la sostenibilidad y la sustentabilidad, la perspectiva intergeneracional, el principio de interseccionalidad, la inclusión y no discriminación, y el principio de corresponsabilidad. "[E]l cuidado de las personas está ligado con el bienestar, la subsistencia y la reproducción de las sociedades y de la fuerza laboral"61. La iniciativa aprobada por la Cámara de Diputados fue turnada a la Cámara de Senadores en donde, de aprobarse, lograría la modificación del artículo $4^{\circ}$ de la Constitución Política de los Estados Unidos Mexicanos para quedar como sigue:

\begin{abstract}
"Toda persona tiene derecho al cuidado digno que sustente su vida y le otorgue los elementos materiales y simbólicos para vivir en sociedad a lo largo de toda su vida, así como a cuidar. El Estado promoverá la corresponsabilidad entre mujeres y hombres en las actividades de cuidado, así como la libertad que tienen las personas para decidir si adquieren o no como obligación el cuidar a quien lo requiera, y el derecho para decidir la distribución del tiempo propio acorde a sus necesidades e intereses. Para garantizar el derecho al cuidado digno se implementará el sistema nacional de cuidados, que incluye sus dimensiones económica, social, política, cultural y biopsicosocial, así como políticas y servicios públicos con base en diseño universal, ajustes razonables, accesibilidad, pertinencia, suficiencia y calidad. La ley establecerá la concurrencia de la Federación, Entidades Federativas, Municipios y demarcaciones territoriales de la Ciudad de México en el sistema nacional de cuidados. Tendrán prioridad en dicho sistema las personas que requieran cuidados por enfermedad, discapacidad, niñas, niños, adolescentes y personas mayores, quienes vivan en condiciones de extrema pobreza, y las personas que realicen actividades de cuidado de las anteriores sin remuneración alguna"62.
\end{abstract}

\footnotetext{
60 Ídem.

61 Ídem.

62 Yo También, Hacia un Sistema Nacional de Cuidados, (23 de octubre de 2020). Disponible en: <https://yotambien.mx/hacia-un-sistema-nacional-de-cuidados/> (última visita 30 de diciembre de 2020).
} 
El artículo 73 de la Constitución Política de los Estados Unidos Mexicanos sobre las facultades del Congreso de la Unión también sería modificado, para agregar una fracción en donde se le faculte a expedir la Ley General del Sistema Nacional de Cuidados que será la encargada de desglosar sus objetivos, funcionamientos y atribuciones.

Es importante que el Sistema Nacional de Cuidados tenga como base la sostenibilidad de la vida humana, en donde coloque en el centro de toda la estructura a las personas, dejando de lado "la mirada androcéntrica de la economía"63. De acuerdo con la ONU, "antes de la COVID-19 en algunos países en desarrollo cerca de la mitad de las personas de edad carecía de acceso a los servicios de salud esenciales"64, por lo que la llegada de la pandemia colocó el tema de la atención a la salud y los cuidados en la agenda pública como una prioridad. Por ello, se celebra que las y los diputados aprobaran la iniciativa para hacer frente a la crisis de cuidados que ha permanecido por años en nuestro país ya que está íntimamente ligada con el acceso al derecho a la salud, el derecho a la igualdad y no discriminación, el acceso a la universalidad de los servicios, el derecho a la vida digna e independiente, entre otros derechos.

\section{1.- La necesidad de brindar una protección especial a las mujeres mayores}

Si bien es importante diseñar una política de protección integral para todas las personas, es importante precisar que ésta debe tomar en consideración las situaciones por las que atraviesan las mujeres mayores y sus experiencias particulares. La creación de un Sistema Nacional de Cuidados es, sin duda, una gran deuda que se tenía con las mujeres mexicanas ${ }^{65}$, pues al crearse este Sistema se avanzará en materia de derechos humanos, e igualdad de género. La creación del Sistema Nacional de Cuidados puede dar respuesta a dos grandes desigualdades que han experimentado las mujeres a lo largo de sus vidas: 1) Dejar de ser las principales cuidadoras del hogar y la familia y 2) Gozar de un sistema integral que las proteja de las desigualdades acumuladas a lo largo de sus vidas para que, al hacerse mayores vivan

\footnotetext{
63 Katrine Marçal, Op. Cit., p.18.

64 Organización de las Naciones Unidas (2020), Op. Cit., p. 3.

65 Al respecto ver Ivonne Thaili Millán Barajas, Desarrollo Económico Nacional: Una deuda histórica con las Mujeres Mexicanas (Letras jurídicas. Revista electrónica de Derecho del Centro Universitario de la Ciénega, Núm. 24, México, 2017).
} 
su vejez con independencia, con participación, con cuidados, con autorrealización y con dignidad ${ }^{66}$.

Baker, Lynch y otras sostienen que las estructuras sociales están incrustadas y reproducidas en los sistemas sociales. El sistema económico, el político, el cultural y el afectivo son especialmente importantes en generar igualdad o desigualdad, debido a su posicionamiento dentro de la vida social en general ${ }^{67}$. En ese sentido, si nos encontramos en una sociedad que privilegia "todas las cualidades que nuestra cultura atribuye tradicionalmente a la masculinidad"68, entonces no es difícil comprender por qué existen tantas desigualdades hacia las mujeres. Tepichin, por su parte, refiere que "la experiencia de la mujer está moldeada por dos dimensiones de la desigualdad social que son fundamentales para la acumulación de activos durante la vida: el género y la pobreza"69. Montes de Oca agrega la edad como categoría de análisis y plantea que "con la acumulación de los años de vida, las desventajas reunidas pasan factura y generan un estado de vida vulnerable socialmente, y frágil en materia de salud"70.

El Comité para la Eliminación de la Discriminación contra la Mujer (CEDAW) en la Recomendación general No 27 sobre las mujeres de edad y la protección de sus derechos humanos refiere que

"[s]i bien tanto el hombre como la mujer son objeto de discriminación a medida que envejecen, las mujeres viven el envejecimiento de distinta forma. El efecto de las desigualdades de género a lo largo de la vida se agrava con la vejez y con frecuencia se basa en normas culturales y sociales hondamente arraigadas. La discriminación que sufren las mujeres de edad suele ser el resultado de una distribución injusta de recursos, malos tratos, abandono y restricción del acceso a servicios básicos"71.

Bajo los estándares capitalistas y patriarcales, las mujeres mayores ya no tienen un lugar digno en la sociedad debido a que ya no

66 Organización de las Naciones Unidas, Los Principios de las Naciones Unidas en favor de las personas de edad, Disponible en:

$<$ https://www.un.org/development/desa/ageing/resources/international-year-of-olderpersons-1999/principles/los-principios-de-las-naciones-unidas-en-favor-de-laspersonas-de-edad.html> (última visita 30 de diciembre de 2020).

67 Baker J.; Lynch K.; Cantillon S.; y Walsh J., Op. Cit., p. 57.

68 Katrine Marçal, Op. Cit., p. 48.

69 Ana María Tepichin Valle, Vulnerabilidades acumuladas. Género y pobreza en la vejez (XXVII Congreso de la Asociación Latinoamericana de Sociología. VIII Jornadas de Sociología de la Universidad de Buenos Aires. Asociación Latinoamericana de Sociología, Buenos Aires, 2009), p. 2.

70 Verónica Montes de Oca, La vejez mexiquense tiene rostro de mujer. Mujeres mayores entre la vulnerabilidad y la fuerza (Mujeres mexiquenses Pasado y presente de las voluntades que transforman, Coord. Emma Liliana Navarrete López, Nuevo pensamiento, 2009), p. 309.

${ }^{71}$ Comité para la Eliminación de la Discriminación contra la Mujer, Op. Cit., párr. 11. 
son productivas desde el punto de vista económico, ni desde el punto de vista reproductivo. Estas ideas conllevan a múltiples discriminaciones que, en muchas ocasiones, se agravan cuando se trata de mujeres mayores indígenas, mujeres mayores con discapacidad, mujeres mayores lesbianas, mujeres mayores migrantes, por ejemplo.

La relación entre género y pobreza se puede explicar desde la división sexual del trabajo, misma que dispone que hay determinadas actividades que son propias de las mujeres y otras de los hombres. Mientras que las primeras se encargan de la esfera privada cuyas labores principales son el trabajo doméstico y de cuidados, los segundos se desenvuelven en la esfera pública, en donde realizan trabajos en el ámbito de la educación, la cultura, la economía, la política, entre muchas otras. De acuerdo con Carrasco, "[e]n esta rígida dualidad sólo el mundo público goza de reconocimiento social. La actividad o participación en la denominada esfera privada, asignada socialmente a las mujeres queda relegada al limbo de lo invisible, negándosele toda posibilidad de valoración social"72.

El trabajo doméstico y de cuidados que han realizado las mujeres a lo largo de sus vidas no son actividades reconocidas, ni remuneradas. En un mundo capitalista y patriarcal el hecho de que las mujeres dediquen más tiempo al trabajo doméstico y de cuidados aumenta las desigualdades ${ }^{73}$. Debido a que las mujeres dedican más años al trabajo doméstico y de cuidados y en ocasiones jamás se incorporan al trabajo remunerado, "cuentan con menos recursos internos y externos (ingresos, estudios, empleo, jubilación, cobertura social, redes de apoyo social y asistencial) para enfrentar los riesgos y cambios inesperados"74.

En México, las mujeres dedican 3 veces más horas al trabajo doméstico y de cuidados que los hombres ${ }^{75}$. En otros casos las mujeres realizan una doble y hasta triple jornada de trabajo, teniendo que

72 Cristina Carrasco, ¿CONCILIACIÓN? NO, GRACIAS. HACIA UNA NUEVA ORGANIZACIÓN SOCIAL (ICARIA, 2003), p. 19.

73 ONU Mujeres, Igualdad de Género a 25 años de Beijing. Los derechos de las mujeres bajo la lupa (2020).

74 Yuliana Gabriela Román-Sánchez; Bernardino Jaciel Montoya-Arce y otros, Los adultos mayores y su retiro del mercado laboral en México (2019). Disponible en: < https://www.redalyc.org/jatsRepo/996/99660265005/html/index.html> (última visita 30 de diciembre de 2020).

75 INEGI, Encuesta Nacional sobre el Uso del Tiempo (ENUT) 2019. Disponible en: <https://www.inegi.org.mx/contenidos/programas/enut/2019/doc/enut 2019 present acion resultados.pdf $>$ (última visita 30 de diciembre de 2020). 
buscar diversas maneras para conciliar su vida personal, profesional y familiar ${ }^{76}$.

Un ejemplo claro se puede observar en el siguiente gráfico:

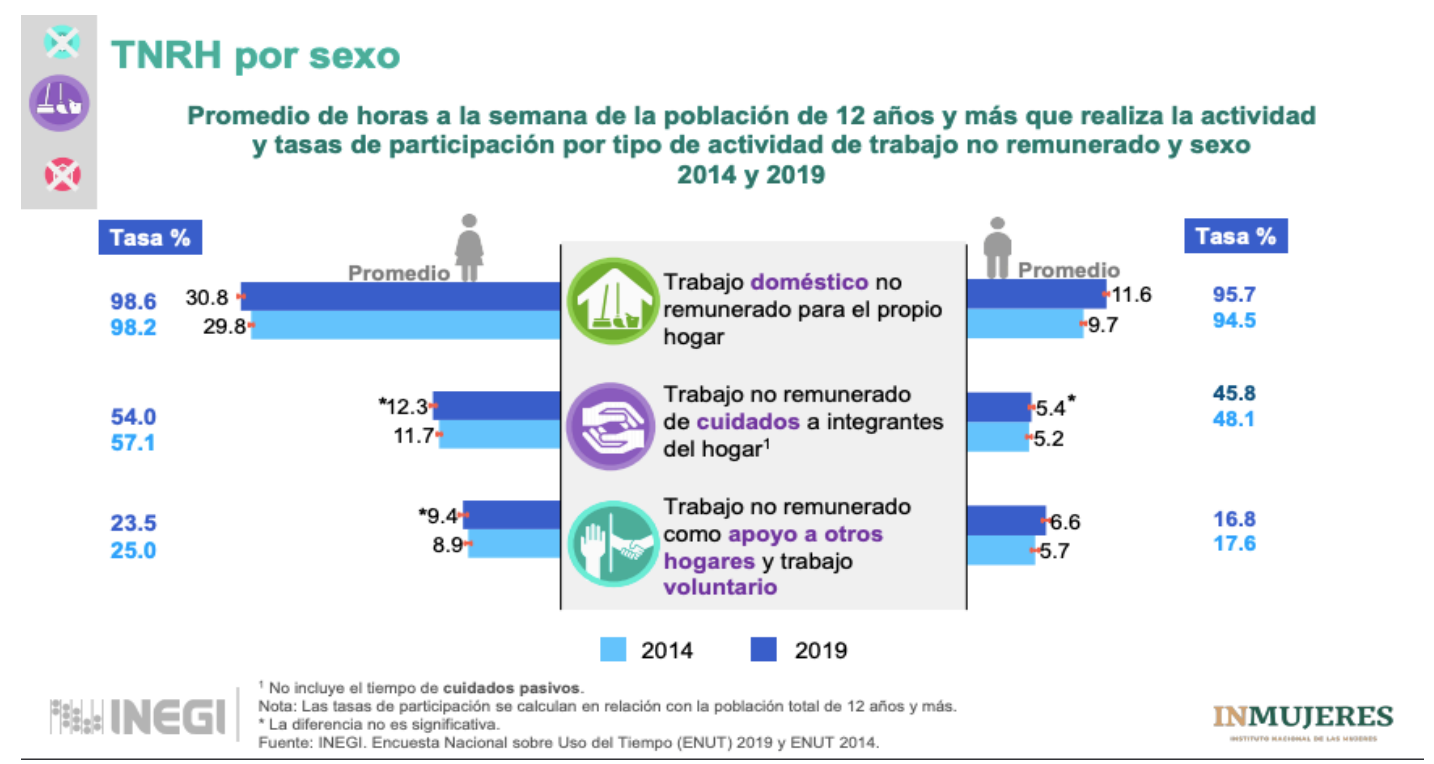

Fuente: INEGI, Encuesta Nacional sobre el Uso del Tiempo (ENUT) 2019.

De acuerdo con el Consejo Nacional de Evaluación de la Política de Desarrollo Social (Coneval), en $2018^{77}$, un 34. 4\% de personas de 65 años y más se encontraban en situación de pobreza moderada y $6.8 \%$ en pobreza extrema. Respecto a las mujeres (sin especificar la edad), un $35 \%$ se encontraba en situación de pobreza moderada y 7.4 en pobreza extrema.

Es importante agregar que los trabajos a los que acceden las mujeres son más precarios, existe una desigualdad salarial, y las mujeres no tienen más remedio que optar por un trabajo de medio tiempo para poder compatibilizar todas sus labores. De acuerdo con la ONU, la brecha salarial de género mundial se mantiene en el $16 \% \mathrm{y}$, en algunos países, las mujeres ganan hasta un 35\% menos que los hombres. En muchos casos esos trabajos son en el sector informal en

76 Cristina Carrasco, Op. Cit.

77 Coneval, Diez años de medición de pobreza multidimensional en México: avances y desafíos en política social. Medición de la pobreza serie 2008-2018. Disponible en: <https://www.coneval.org.mx/Medicion/MP/Documents/Pobreza 18/Pobreza 2018 C ONEVAL.pdf $>$ (última visita 31 de diciembre de 2020). 
donde no tendrán acceso al sistema de pensiones ${ }^{78}$. De acuerdo con la ONU, en el mundo, 740 millones de mujeres trabajan en la economía informal y cuando las mujeres llegan a una edad adulta estas situaciones no mejoran, sino más bien empeoran.

Al llegar a la vejez, las mujeres experimentan una gran vulnerabilidad, por lo que se habla de feminización de la vejez debido a que "la mujer tiende a ser más longeva que el hombre y que el número

de mujeres de edad que viven solas supera al de hombres en la misma situación"79. Una de las desigualdades que experimentan las mujeres mayores es respecto a su situación económica, ya que no cuentan con ahorros suficientes y "su situación económica y social depende de una serie de factores demográficos, políticos, ambientales, culturales, sociales, individuales y familiares"80. En México, el $23,9 \%$ de las mujeres mayores no poseen un ingreso propio ${ }^{81}$, y es más crítico en el caso de las adultas mayores que viven en zonas rurales de las cuales el $29,7 \%$ no percibe un ingreso propio ${ }^{82}$. Montes de Oca explica que "gran parte de las ventajas o desventajas en la vida adulta y adulta mayor tiene que ver con ese espacio que se ocupa o se ha ocupado en el tiempo de vida"83. Así, si el espacio que han ocupado las mujeres es en el ámbito privado entonces existen grandes desigualdades. Esto se debe a que "todas las actividades relacionadas con el sostenimiento de la vida humana, que tradicionalmente han realizado las mujeres y que en gran medida se caracterizan porque su resultado desaparece en el desarrollo de la actividad, no han sido valoradas" 84 .

En México, el $19.4 \%$ de las mujeres mayores se encuentran en el mercado laboral; sin embargo, muchas de ellas trabajan en el sector informal, aunque "[I]a actividad más frecuente de las adultas mayores es el trabajo no remunerado. Un $62.8 \%$ de ellas se dedican a los quehaceres domésticos, actividad que muy probablemente han desarrollado toda su vida, y la cual realiza solamente $8.0 \%$ de los hombres"85. La gran mayoría de las mexicanas han dedicado muchos años al trabajo doméstico y de cuidados no remunerado. Además,

\footnotetext{
78 UNFPA, Op. Cit., p. 23.

${ }^{79}$ Comité para la Eliminación de la Discriminación contra la Mujer, Op. Cit., párr. 5.

80 Comité para la Eliminación de la Discriminación contra la Mujer, Op. Cit., párr. 8.

81 En el caso de los adultos mayores varones, el $9 \%$ no poseen un ingreso propio.

82 CEPAL (2020, Op. Cit., p. 28.

83 Verónica Montes de Oca, Op. Cit., p. 316.

84 Cristina Carrasco, Op. Cit., p. 20.

${ }^{85}$ Instituto Nacional de las Mujeres, Situación de las personas adultas mayores en

México, Disponible en:

<http://cedoc.inmujeres.gob.mx/documentos download/101243 1.pdf > (última visita 01 de enero de 2021).
} 
"las mujeres adultas mayores que desarrollan las actividades del hogar son prácticamente invisibles. Lo anterior facilita la desprotección y la vulnerabilidad a tratos desiguales, injustos, abusivos, ya que estas trabajadoras no tienen cobertura de seguridad social y sus remuneraciones son bajas. Esto significa, entre otras cosas, que no pueden acceder al derecho a una pensión, servicios de guardería y pago de incapacidades, entre otros beneficios" ${ }^{16}$.

Asimismo, "[l]a baja participación de las mujeres en el mercado laboral y su inserción en condiciones precarias llevan a que la proporción de mujeres jubiladas sea aún menor que la de los hombres"87. De hecho, "[s]olamente un $8.7 \%$ de las mujeres adultas mayores está pensionada o jubilada, o recibe pensión por viudez"88, lo cual es alarmante ya que viven con un ingreso económico bajo lo cual acrecenta las desigualdades que pueden llegar a sufrir.

"[L]as necesidades de cuidado se incrementan conforme aumenta la edad"89. El factor de la edad no es el único criterio que determina la necesidad de cuidado, pues el género, o las condiciones de pobreza, y discapacidad, por ejemplo, son factores determinantes en la vida de las personas y en su proyecto de vida. Encontrarse en una situación de múltiple vulnerabilidad, las conduce a "la debilidad e inseguridad personal para enfrentar los riesgos y cambios en la vejez como viudez, soledad, discriminación y maltrato"90.

Las mujeres mayores tienen acumuladas una serie de desventajas que juegan en su contra al llegar a la vejez. Es por ello que se requiere de un Sistema de Cuidados bien articulado que tenga en cuenta las

desigualdades que han experimentado a lo largo de su vida para poder incorporar una mirada crítica a cualquier intento de pasar por alto las diferencias vividas entre varones y mujeres. Por otro lado, es importante tener en cuenta que

"la etapa de transición demográfica en que se encuentra nuestro país supone una demanda más elevada de servicios, especialmente asociada al incremento de personas adultas mayores que generará un impacto en el Sistema de Salud y desafíos a la organización familiar, así como cargas adicionales de trabajo de

\footnotetext{
86 Yuliana Gabriela Román-Sánchez; Bernardino Jaciel Montoya-Arce y otros, Op. Cit.

87 Instituto Nacional de las Mujeres, Op. Cit.

88 Ídem.

89 Ídem.

90 Yuliana Gabriela Román-Sánchez; Bernardino Jaciel Montoya-Arce y otros, Op. Cit.
} 
cuidados, en especial para las mujeres, quienes realizan mayoritariamente este trabajo. Esta situación se acentuará en el futuro debido a que los grupos de edades más avanzadas constituirán una proporción mayor; en 2014 las y los mayores de 80 años representan $15.1 \%$ de personas adultas mayores y en 2050 serán casi $20 \% " 91$.

Como se puede observar en el gráfico, hay un mayor número de mujeres que de hombres, y éstas viven más años. Para 2050 esta tendencia habrá aumentado considerablemente.

\begin{tabular}{|c|c|c|c|c|c|c|}
\hline Grupos de edad & Mujeres & Hombres & Total & Mujeres & Hombres & Total \\
\hline \multicolumn{7}{|c|}{2010} \\
\hline Total & $5,375,841$ & $4,679,538$ & $10,055,379$ & 100.0 & 100.0 & 100.0 \\
\hline 60 a 69 años & $2,861,791$ & $2,571,940$ & $5,433,731$ & 53.2 & 55.0 & 54.0 \\
\hline 70 a 79 años & $1,665,835$ & $1,453,582$ & $3,119,417$ & 31.0 & 31.1 & 31.0 \\
\hline 80 años y más & 848,215 & 654,016 & $1,502,231$ & 15.8 & 14.0 & 14.9 \\
\hline \multicolumn{7}{|c|}{2014} \\
\hline Total & $6,267,693$ & $5,401,740$ & $11,669,431$ & 100 & 100 & 100 \\
\hline 60 a 69 años & $3,400,876$ & $3,034,205$ & $6,435,080$ & 54.3 & 56.2 & 55.1 \\
\hline 70 a 79 años & $1,872,979$ & $1,600,977$ & $3,473,955$ & 29.9 & 29.6 & 29.8 \\
\hline 80 años y más & 993,838 & 766,558 & $1,760,396$ & 15.9 & 14.2 & 15.1 \\
\hline \multicolumn{7}{|c|}{2050} \\
\hline Total & $18,182,536$ & $14,244,659$ & $32,427,197$ & 100 & 100 & 100 \\
\hline 60 a 69 años & $8,332,700$ & $6,875,120$ & $15,207,821$ & 45.8 & 48.3 & 46.9 \\
\hline 70 a 79 años & $6,138,609$ & $4,765,267$ & $10,903,877$ & 33.8 & 33.5 & 33.6 \\
\hline 80 años y más & $3,711,227$ & $2,604,272$ & $6,315,499$ & 20.4 & 18.3 & 19.5 \\
\hline
\end{tabular}

Fuente: Inmujeres con base en INEGI. Censo de Población y Vivienda 2010. Consulta interactiva

CONAPO. Proyecciones de la Población 2010-2050

Fuente: Instituto Nacional de las Mujeres.

El hecho de que las mujeres vivan más años no implica que lo hacen en condiciones dignas. De hecho, "[I]as mujeres padecen enfermedades incapacitantes más graves y por más largo tiempo"92, como se muestra en el siguiente gráfico:

91 Instituto Nacional de las Mujeres, Op. Cit. 92 Ídem. 


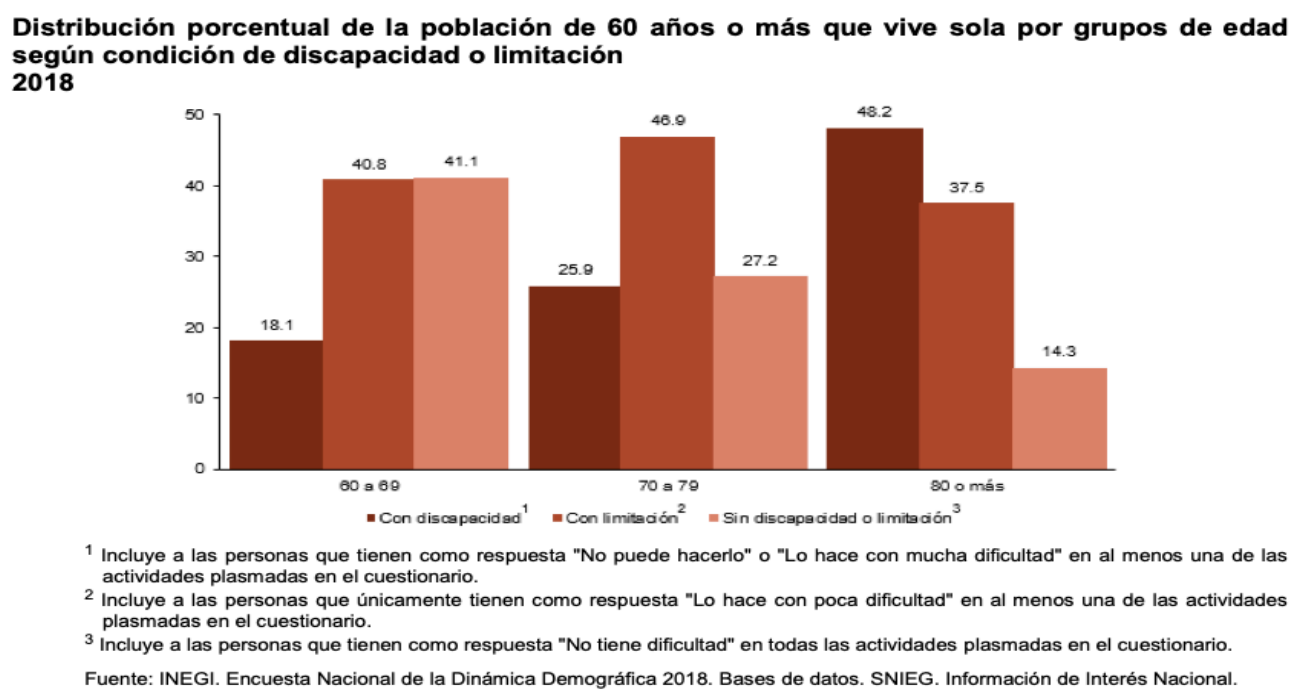

Fuente: INEGI, Estadísticas a propósito del Día Internacional de las Personas de Edad (10 de octubre). Disponible en:

https://www.inegi.org.mx/contenidos/saladeprensa/aproposito/2019/edad2019 nal.pd f.

Asimismo, "los cambios biológicos ocurridos durante su ciclo reproductivo y el paso transicional hacia la etapa post reproductiva (...), las condiciona a un riesgo adicional de padecer enfermedades crónicas"93.

Por otro lado, el estado civil de las mujeres mayores tiene un gran impacto en sus vidas. Como se aprecia en el siguiente gráfico, un pequeño porcentaje de ellas vive en concubinato o está casada, en contraste con el porcentaje de hombres. Un $65.3 \%$ de las mujeres mayores es viuda, en comparación con un $42.6 \%$ de hombres. Esto es en parte porque las mujeres viven más años y en parte porque muchas no vuelven a casarse 0 a vivir con alguien como sí sucede con los varones. Estos datos sugieren que mientras que los hombres viven con alguien que, muy seguramente les provee de cuidados, las mujeres mayores viven solas y tienen una necesidad mayor de recibir cuidados.

93 Ídem. 

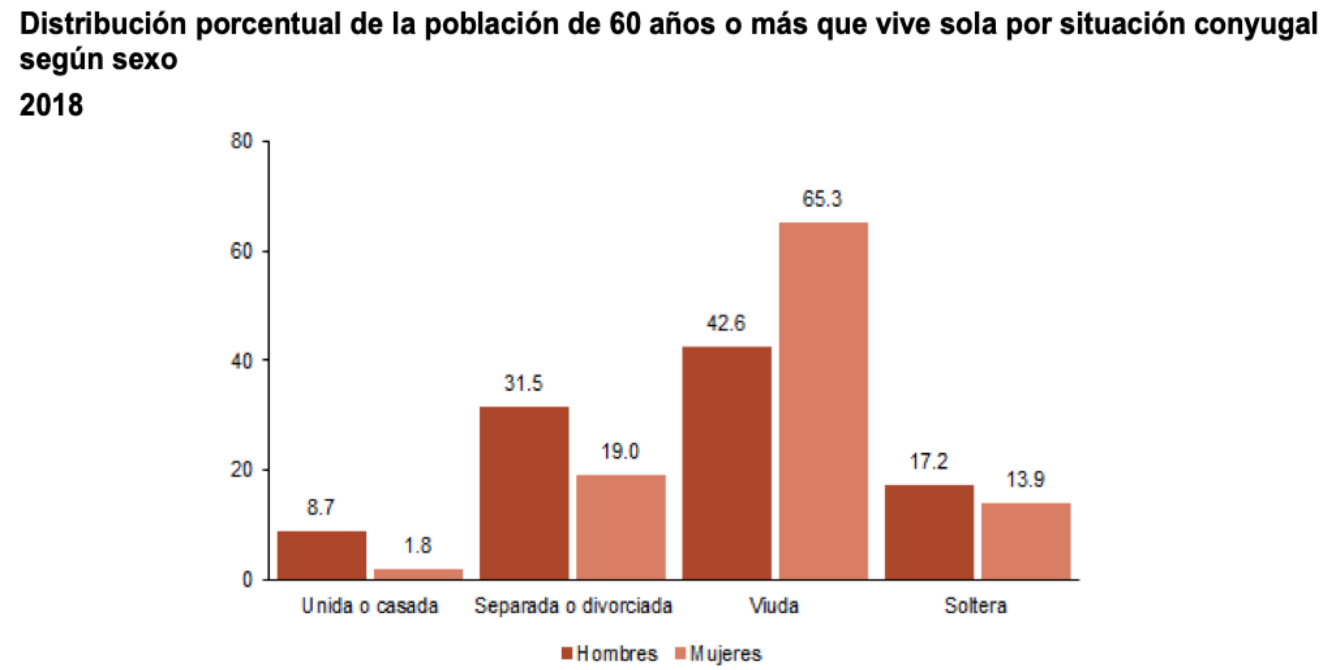

Fuente: INEGI. Encuesta Nacional de la Dinámica Demográfica 2018. Bases de datos. SNIEG. Información de Interés Nacional.

Fuente: INEGI, Estadísticas a propósito del Día Internacional de las Personas de Edad (10 de octubre).

Finalmente, tener en cuenta las particularidades de las personas mayores $y$, especialmente de las mujeres mayores, invita a reflexionar sobre cómo deberá componerse el Sistema Nacional de Cuidados en México, cómo deberá operar, qué instituciones serán las responsables, qué objetivos se tendrá que plantear y si el no asignar recursos específicos para su operatividad es realmente parte de la solución o será un obstáculo más para alcanzar un cambio significativo en la vida de las personas que se beneficiarán directa e indirectamente del Sistema.

\section{4.- CONCLUSIÓN}

Los datos presentados demuestran gráficamente las grandes desigualdades que viven las mujeres mayores en México y la importancia y necesidad de contar con un sistema integral de cuidados que tenga en cuenta todas estas desigualdades para que, a la hora de emitir la ley que regirá el Sistema Nacional de Cuidados y su reglamento, éstas sean una respuesta acertada que brinde un conjunto de soluciones que contribuyan a que las mujeres mayores vivan una vejez con dignidad sin que esta etapa sea la culminación agravada de una serie de vulnerabilidades en su vida, sino una etapa que pueda vivirse con plenitud y que, de cierta manera, pueda compensarlas por no haber adoptado mecanismos similares previamente.

Aunque este artículo fue solo un primer acercamiento al tema, y no tuvo como objetivo abundar en modelos de sistemas de cuidados o de buenas prácticas en otros países, pretende contribuir a dejar una base para futuras investigaciones, ya que además de plantear un 
contexto, también es importante aportar una mirada crítica al debate $y$, sobretodo, proponer una ruta que tenga en cuenta la perspectiva de género y de derechos humanos.

\section{5.- BIBLIOGRAFÍA}

Amoroso Miranda María Inés; Bosch Pareras Anna; Carrasco Bengoa Cristina y otras, Malabaristas de la vida. Mujeres, tiempos y trabajos (ICARIA, 2003).

Baker J.; Lynch K.; Cantillon,S.; y Walsh J., Equality: From Theory to Action (New York, MacMillan ,2004).

Cámara de Diputados, Comisión de Puntos Constitucionales. Proyecto de Dictamen de las Comisión de Puntos Constitucionales por el que se reforman los artículos 40 Y 73 de la Constitución Política de los Estados Unidos Mexicanos, en materia de Sistema Nacional De Cuidados.

Carrasco Cristina, ¿CONCILIACIÓN? NO, GRACIAS. HACIA UNA NUEVA ORGANIZACIÓN SOCIAL, (ICARIA, 2003).

CEPAL, COVID-19 y sus impactos en los derechos y la protección social de las personas mayores en la subregión (2020).

CEPAL, COVID-19 Recomendaciones generales para la atención a personas mayores desde una perspectiva de derechos humanos (2020 a).

Comisión Nacional de los Derechos Humanos, El derecho a la no discriminación (2018).

Comisión Nacional de los Derechos Humanos, Informe Especial sobre la Situación de los Derechos Humanos de las Personas Mayores en México (2019).

Comité para la Eliminación de la Discriminación contra la Mujer, Recomendación general No 27 sobre las mujeres de edad y la protección de sus derechos humanos, CEDAW/C/GC/27, 16 de diciembre de 2010.

Comité sobre los Derechos de las Personas con Discapacidad, Observación general núm. 6 (2018) sobre la igualdad y la no discriminación, CRPD/C/GC/6, (26 de abril de 2018).

Coneval, Diez años de medición de pobreza multidimensional en México: avances y desafíos en política social. Medición de la pobreza serie 2008-2018.

Disponible

en:

$<$ https://www.coneval.org.mx/Medicion/MP/Documents/Pobreza 1 8/Pobreza 2018 CONEVAL.pdf> 
Corte Interamericana de Derechos Humanos, Caso Espinoza Gonzáles Vs. Perú. Sentencia de 20 de Noviembre de 2014 (Excepciones Preliminares, Fondo, Reparaciones y Costas).

Corte Interamericana de Derechos Humanos, Cuadernillo de Jurisprudencia de la Corte Interamericana de Derechos Humanos No. 14: Igualdad y No Discriminación (2019).

de Beauvoir Simone, La Vejez (Debolsillo, 2016).

Equis Justicia para las Mujeres, Las dos pandemias. Violencia contra las mujeres en México en el contexto de Covid-19 (2020).

Instituto Nacional de las Mujeres, Situación de las personas adultas mayores en México.

Ley Federal para prevenir y eliminar la discriminación, publicada en el DOF el 13 de junio de 2002.

Ley de los Derechos de las Personas Adultas Mayores, publicada en el DOF el 25 de junio de 2002.

Marçal Katrine, ¿Quién le hacía la cena a Adam Smith? (Debate, 2016). Millán Barajas Ivonne Thaili, Desarrollo Económico Nacional: Una deuda histórica con las Mujeres Mexicanas (Letras jurídicas. Revista electrónica de Derecho del Centro Universitario de la Ciénega, Núm. 24, México, 2017).

Millán Barajas Ivonne Thaili, Trata de mujeres con fines de explotación sexual en México, (Revista Jurídica Jalisciense, año xxviii, núm. 59. Julio-diciembre 2018).

Montes de Oca Verónica, La vejez mexiquense tiene rostro de mujer.

Mujeres mayores entre la vulnerabilidad y la fuerza (en Mujeres mexiquenses Pasado y presente de las voluntades que transforman, Coord. Emma Liliana Navarrete López, Nuevo pensamiento, $1^{\text {a }}$ ed., México, 2009).

Organización de las Naciones Unidas, Convención Interamericana sobre la Protección de los Derechos Humanos de las Personas Mayores, depositada por la Secretaría General OEA y adoptada en Washington, D.C., Estados Unidos. Entró en vigor el 11 de enero de 2017.

Organización de las Naciones Unidas, Informe de políticas: Los efectos de la COVID-19 en las personas de edad (2020).

Organización de las Naciones Unidas, Informe de la Experta Independiente sobre el disfrute de todos los derechos humanos por las personas de edad, Claudia Mahler, Impacto de la 
enfermedad por coronavirus (COVID-19) en el disfrute de todos los derechos humanos por las personas de edad, A/75/205, 21 de julio de 2020.

Organización de las Naciones Unidas, Los Principios de las Naciones Unidas en favor de las personas de edad.

ONU Mujeres, Igualdad de Género a 25 años de Beijing. Los derechos de las mujeres bajo la lupa (2020).

Organización Mundial de la Salud, Preguntas y respuestas sobre la enfermedad por coronavirus (COVID-19), Disponible en: $<$ https://www.who.int/es/emergencies/diseases/novelcoronavirus-2019/advice-for-public/q-acoronaviruses?gclid=CjwKCAiAxeX BRASEiwAc1QdkWEIXjGmCMN ScBJJ Ibp6oL1ZtYouMF71wUSS9VB HVz6kAY2fg7WBoCBn8QAvD BwE>

Perez Pacheco Francisco Alberto y Macias Sánchez Alejandra, Adultos mayores y COVID-19: Vulnerabilidad económica ante la crisis sanitaria (Centro de Investigación Económica y Presupuestaria, A. C., 2020).

Pleno de la Suprema Corte de Justicia de la Nación, Acción de inconstitucionalidad 8/2014. Ministra Margarita Beatriz Luna Ramos.

Román-Sánchez Yuliana Gabriela; Montoya-Arce Bernardino Jaciel, y otros, Los adultos mayores y su retiro del mercado laboral en México (Soc. Econ. [online]. n.37, pp.87-113. ISSN 1657-6357. <http://dx.doi.org/10.25100/sye.v0i37.7823>, 2019).

Segunda Sala de la Suprema Corte de Justicia de la Nación, Amparo en Revisión 710/2016, Ministro: Javier Laynez Potisek.

Senado de la República, Gaceta de la Comisión Permanente, Del Dip. Evelio Plata Inzunza, del Grupo Parlamentario del Partido Revolucionario Institucional, con proyecto de decreto que reforma el artículo 5o. de la Ley de los Derechos de las Personas Adultas Mayores.

Disponible

en: $<$ https://www.senado.gob.mx/64/gaceta comision permanente/d ocumento/81611>

Tepichin Valle Ana María, Vulnerabilidades acumuladas. Género y pobreza en la vejez (XXVII Congreso de la Asociación Latinoamericana de Sociología. VIII Jornadas de Sociología de la Universidad de Buenos Aires. Asociación Latinoamericana de Sociología, Buenos Aires, 2009).

UNFPA, Una mirada sobre el envejecimiento. ¿Dónde están varios países latinoamericanos a 15 años del Plan de Acción Internacional de Madrid? (2017). 
Yo También, Hacia un Sistema Nacional de Cuidados, (23 de octubre de 2020). Disponible en: <https://yotambien.mx/hacia-un-sistemanacional-de-cuidados/>

\section{1.- Fuentes de Datos}

ENADIS 2017. Principales resultados. Disponible en: $<$ https://www.inegi.org.mx/contenidos/programas/enadis/2017/d oc/enadis2017 resultados.pdf>

INEGI, Encuesta Nacional sobre el Uso del Tiempo (ENUT) 2019. Disponible

en: $<$ https://www.inegi.org.mx/contenidos/programas/enut/2019/doc Lenut 2019 presentacion resultados.pdf>

\section{2.- Otras referencias}

Cámara de Diputados [Mx_Diputados]. (18 de noviembre de 2020). 329 votos a favor, 0 en contra y 0 abstenciones. Aprueban, en lo general, el dictamen que reforma y adiciona los artículos 4 y 73 de la Constitución Política, en materia de sistema nacional de cuidados. [Tuit]. Recuperado de <https://twitter.com/Mx Diputados/status/132924415365869977 6?ref src $=$ twsrc\%5Etfw\%7Ctwcamp\%5Etweetembed\%7Ctwterm \%5E1329244153658699776\%7Ctwgr\%5E\%7Ctwcon\%5Es1 \&ref url=https \%3A\%2F\%2Fwww.milenio.com\%2Fpolitica\%2Fsistemanacional-cuidados-avalado-camara-diputados $>$

Gobierno de México, Adultos Mayores. Disponible en: $<$ https://coronavirus.gob.mx/adultos-mayores/> (última visita el 26 de diciembre de 2020).

Gobierno de México, Pensión Universal para Personas Adultas Mayores. Disponible en: <https://www.gob.mx/pensionpersonasadultasmayores>

Gobierno de México, Programa de Pensión para el Bienestar de las Personas Adultas Mayores. Disponible en: $<$ https://presidente.gob.mx/programa-de-pension-para-elbienestar-de-las-personas-adultas-mayores/>

Gobierno de México, Quédate en Casa. Disponible en: $<$ https://coronavirus.gob.mx/quedate-en-casa/> 